Article

\title{
Pressureless Sintering of YIG Ceramics from Coprecipitated Nanopowders
}

\author{
Yimin Yang 1,2, Xiaoying $\mathrm{Li}^{2,3}$, Ziyu Liu ${ }^{2,3}$, Dianjun $\mathrm{Hu}^{2,3}$, Xin Liu ${ }^{2,3}$, Penghui Chen ${ }^{2,3}$, Feng Tian ${ }^{2,3}$, \\ Danyang Zhu ${ }^{2,3}$, Lixuan Zhang ${ }^{2,3}$ and Jiang $\mathrm{Li}^{2,3, *}$ \\ 1 School of Materials Science and Engineering, Jilin Jianzhu University, Changchun 130118, China; \\ yym1589261518@163.com \\ 2 Key Laboratory of Transparent Opto-Functional Inorganic Materials, Shanghai Institute of Ceramics, \\ Chinese Academy of Sciences, Shanghai 201899, China; lixiaoying19@mails.ucas.ac.cn (X.L.); \\ liuziyu@student.sic.ac.cn (Z.L.); hudianjun@student.sic.ac.cn (D.H.); liuxin@student.sic.ac.cn (X.L.); \\ chenpenghui20@mails.ucas.ac.cn (P.C.); tianfeng@student.sic.ac.cn (F.T.); \\ zhudanyang@student.sic.ac.cn (D.Z.); zhanglixuan@student.sic.ac.cn (L.Z.) \\ 3 Center of Materials Science and Optoelectronics Engineering, University of Chinese Academy of Sciences, \\ Beijing 100049, China \\ * Correspondence: lijiang@mail.sic.ac.cn; Tel.: +86-21-69163689; Fax: +86-21-69906700
}

Citation: Yang, Y.; Li, X.; Liu, Z.; Hu, D.; Liu, X.; Chen, P.; Tian, F.; Zhu, D.;

Zhang, L.; Li, J. Pressureless Sintering of YIG Ceramics from Coprecipitated Nanopowders. Magnetochemistry 2021, 7, 56. https://doi.org/ 10.3390/magnetochemistry7050056

Academic Editors: Dmitry Permin and Lotfi Bessais

Received: 5 March 2021

Accepted: 21 April 2021

Published: 25 April 2021

Publisher's Note: MDPI stays neutral with regard to jurisdictional claims in published maps and institutional affiliations.

Copyright: (c) 2021 by the authors. Licensee MDPI, Basel, Switzerland. This article is an open access article distributed under the terms and conditions of the Creative Commons Attribution (CC BY) license (https:/ / creativecommons.org/licenses/by/ $4.0 /)$.

\begin{abstract}
Nanoparticles prepared by the coprecipitation method were used as raw materials to fabricate $\mathrm{Y}_{3} \mathrm{Fe}_{5} \mathrm{O}_{12}$ (YIG) ceramics by air pressureless sintering. The synthesized YIG precursor was calcinated at $900-1100^{\circ} \mathrm{C}$ for $4 \mathrm{~h}$ in air. The influences of the calcination temperature on the phase and morphology of the nanopowders were investigated in detail. The powders calcined at $1000-1100{ }^{\circ} \mathrm{C}$ retained the pure YIG phase. YIG ceramics were fabricated by sintering at $1200-1400{ }^{\circ} \mathrm{C}$ for $10 \mathrm{~h}$, and its densification behavior was studied. YIG ceramics prepared by air sintering at $1250{ }^{\circ} \mathrm{C}$ from powders calcinated at $1000^{\circ} \mathrm{C}$ have the highest in-line transmittance in the range of $1000-3000 \mathrm{~nm}$. When the sintering temperature exceeds $1300^{\circ} \mathrm{C}$, the secondary phase appears in the YIG ceramics, which may be due to the loss of oxygen during the high-temperature sintering process, resulting in the conversion of $\mathrm{Fe}^{3+}$ into $\mathrm{Fe}^{2+}$.
\end{abstract}

Keywords: YIG ceramics; coprecipitation method; calcination temperature; pressureless sintering

\section{Introduction}

In modern optical fiber communication and information processing systems, the Faraday isolator is a crucial device that can ensure more reliable performance of the laser source and nonreciprocal photonic transmission by eliminating the back reflections [1,2]. The core component of the Faraday isolator is magneto-optical materials [3]. The essential requirements of magneto-optical materials are a large Verdet constant, low absorption, and a low saturated magnetizing field $[4,5]$. Iron garnets represented by $\mathrm{YIG}\left(\mathrm{Y}_{3} \mathrm{Fe}_{5} \mathrm{O}_{12}\right)$ have a light transmission function in wavelength longer than $1.2 \mu \mathrm{m}$ and exhibit ferrimagnetic properties, and thus they possess a much larger Faraday rotation angle than the paramagnetic $\mathrm{Tb}_{3} \mathrm{Ga}_{5} \mathrm{O}_{12}$ (TGG) or $\mathrm{Tb}_{3} \mathrm{Al}_{5} \mathrm{O}_{12}$ (TAG) Faraday rotator materials [6-14]. As a promising material used in optical isolators, YIG crystal has been widely researched. As we all know, cerium or bismuth-substituted yttrium iron garnets can enhance the Faraday rotation angle greatly [15]. Normally, Bi- and Ce-doped YIG materials are produced by the FZ (floating zone method) or LPE (liquid phase epitaxial) method [16-20]. According to the phase equilibrium diagram of the system iron oxide $\mathrm{YFeO}_{3}$ (YIP), it is difficult to grow iron garnet crystals by traditional methods owing to the incongruent melting nature [21]. Although many approaches have been proposed to solve this problem, the size of the obtained YIG single crystal is still limited, which leaves it far from practical application. In recent years, with the rapid development of optical ceramic technology, the transparent ceramic materials may challenge single crystals because of their excellent properties [22,23]. 
Ikesue et al. [24]. succeeded for the first time in the synthesis of the infrared transparent YIG ceramics whose optical loss was small in the near-mid-infrared region to be usable for isolators in telecommunication and whose magneto-optical properties were comparable to the YIG single crystal grown by the FZ method. Subsequently, they synthesized Bi-doped iron garnet by a solid-state reaction sintering method, and also confirmed that the magneto-optical properties of polycrystalline Bi:YIG ceramics were equivalent to single crystal [25]. At the same time, they successfully prepared transparent $\mathrm{Tb}_{3} \mathrm{Fe}_{5} \mathrm{O}_{12}$ (TIG) ceramics for a 1.3-1.5 $\mu \mathrm{m}$ optical isolator by solid-state reaction of $\mathrm{Tb}_{4} \mathrm{O}_{7}$ and $\mathrm{Fe}_{2} \mathrm{O}_{3}$ [26]. In 2020, Ikesue et al. reported that Ce was added to the ferromagnetic YIG ceramics to achieve giant magneto-optical properties. Doping Ce in iron garnet can give a Faraday rotation function around 5 times higher than that of Bi:YIG (29 deg./ $\mathrm{cm}$ per $1 \mathrm{at} . \%$ of Bi), which is currently used in optical isolators for telecommunications [27].

YIG transparent ceramics can avoid the incongruent melting problem since it can be produced at the lower sintering temperature without the melting process. Additionally, polycrystalline ceramic materials have many other advantages, such as low fabrication and time cost, large scalable size, and excellent mechanical and thermal properties. At present, besides the application of advanced sintering techniques, more attention has been paid to the synthesis routes of the powders since the characteristics of powder can affect the final ceramics to a great extent. Pure low-agglomerated powders with high sinterability are essential for transparent ceramics with full density and ideal microstructural features [28]. It is well known that the coprecipitation method is an effective route to synthesize powders possessing proper characteristics toward transparent ceramics. The characteristics of the coprecipitated powders are sensitive to the nature of the mixed salts solution and precipitant as well as synthesis conditions [29-31]. According to $\mathrm{Hu}$ [32] et al., calcination temperature has a significant influence on the dispersity, grain growth, and sinterability of nanopowders. The powders calcined at a lower temperature often have a large specific surface area and they cannot be easily compacted into the uniform green body. On the other hand, an excessive calcination temperature easily causes severe agglomeration and loses some sinterability of the powders. The sintering temperature is also critical to the performance of ceramics. When the temperature is too low, the grain growth is not complete, and the degree of densification is not high. When the sintering temperature is too high, intragranular pores may appear due to the difference in the rate of grain boundary migration and grain boundary diffusion, and vitrification may occur in more serious cases [33]. Therefore, the aim of this paper was to investigate the role of the calcination temperature, and the appropriate calcination temperature for optimal powders for YIG transparent ceramics was selected. It provides a valuable reference for the preparation and performance improvement of YIG ceramics in the future.

In this paper, the synthesis of the YIG nanoparticles by the coprecipitation method using ammonium hydrogen carbonate (AHC) as the precipitant was reported. The effects of calcination temperature on the phase composition, morphology, and particle size of YIG powders were systematically studied. Subsequently, YIG transparent ceramics were prepared by pressureless sintering with the prepared YIG nanopowders as raw materials. The in-line transmittance and microstructure of YIG ceramics by the different sintering methods were studied.

\section{Results and Discussion}

Figure 1 shows the $X$-ray diffraction data of the precursor and the synthesized powders calcined at different temperatures for $4 \mathrm{~h}$. As can be seen, the spectrum of the coprecipitated precursor exhibits low crystallinity, which is common in the coprecipitation method due to the low crystallite growth driving force. The powders calcined at 900 and $950{ }^{\circ} \mathrm{C}$ show diffraction peaks of $\mathrm{Fe}_{2} \mathrm{O}_{3}$ and $\mathrm{YFeO}_{3}$, indicating that the calcination temperature is insufficient and the reaction is incomplete. The diffraction peaks of the powders calcined above $1000{ }^{\circ} \mathrm{C}$ are consistent with the cubic structure of YIG (JCPDS: 43-0507). By increasing the calcination temperature up to $1100^{\circ} \mathrm{C}$, the calcined powders show a continuous increase 
in the intensity of the diffraction peaks, indicating the improved crystallinity. Therefore, $\mathrm{Y}_{3} \mathrm{Fe}_{5} \mathrm{O}_{12}$ is formed through two successive transformations during the calcination process [34]. The reaction equations can be listed as follows:

$$
\begin{gathered}
\mathrm{Y}_{2} \mathrm{O}_{3}+\mathrm{Fe}_{2} \mathrm{O}_{3} \rightarrow 2 \mathrm{YFeO}_{3}(\mathrm{YIP}), \\
3 \mathrm{YFeO}_{3}+\mathrm{Fe}_{2} \mathrm{O}_{3} \rightarrow \mathrm{Y}_{3} \mathrm{Fe}_{5} \mathrm{O}_{12}(\mathrm{YIG})
\end{gathered}
$$

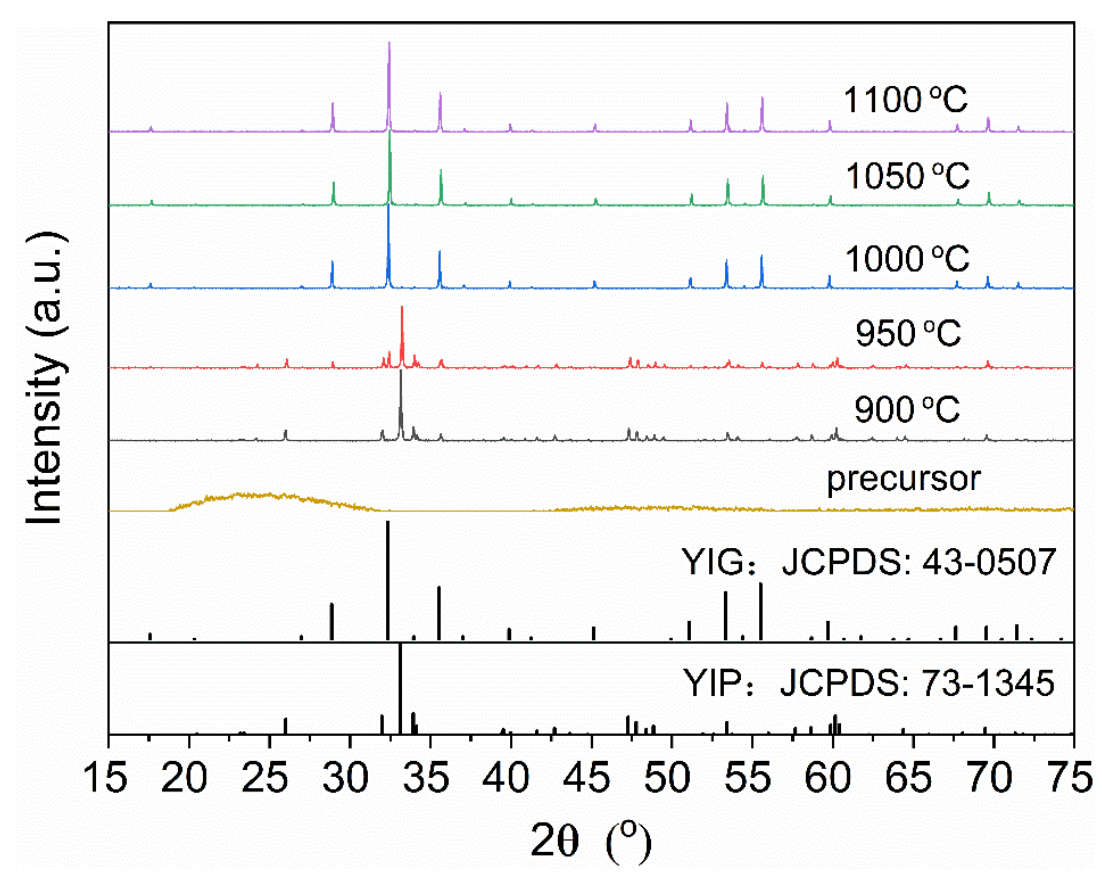

Figure 1. XRD patterns of the as-synthesized precursor and the powders calcined at different temperatures for $4 \mathrm{~h}$.

The average crystallite sizes $\left(\mathrm{D}_{\mathrm{XRD}}\right)$ of the YIG powders calcined at different temperatures were calculated from the XRD spectra using the Scherrer equation. The formula is shown as follows [35]:

$$
\mathrm{D}_{\mathrm{XRD}}=0.89 \lambda /(\beta \cdot \cos \theta)
$$

where $\lambda$ is the wavelength of $\mathrm{Cu} \mathrm{K}_{\alpha}$ radiation, and $\beta$ is the full width at half maximum (FWHM) of a diffraction peak at Bragg angle $\theta$. It can be seen that the average crystallite size increases from $66 \mathrm{~nm}$ to $75 \mathrm{~nm}$ with the calcination temperature increases from $1000{ }^{\circ} \mathrm{C}$ to $1100{ }^{\circ} \mathrm{C}$.

The FTIR spectra of the as-synthesized precursor and the powders calcined at 900, 950, 1000, 1050, and $1100{ }^{\circ} \mathrm{C}$ are illustrated in Figure 2. As to the precursor, a broad absorption band around $3440 \mathrm{~cm}^{-1}$ is assigned to the stretching modes of $\mathrm{O}-\mathrm{H}$ bonds in yttrium/iron hydroxides, ethanol, and water while the band at $1627 \mathrm{~cm}^{-1}$ may correspond to the H-O-H bending mode of molecular water [36]. Furthermore, these absorption bands vanish with the calcination temperature increasing. The bands at 2360 and $1520 \mathrm{~cm}^{-1}$ are indicative of the $\mathrm{NH}^{4+}$ radicals and the ones around 1384 and $841 \mathrm{~cm}^{-1}$ are due to the $\mathrm{NO}^{3-}$ radicals $[37,38]$. In addition, the bands at $1086 \mathrm{~cm}^{-1}$ arise from the $\mathrm{C}-\mathrm{H}$ stretching vibrations and the broad band around $465 \mathrm{~cm}^{-1}$ largely corresponds to the vibrations of $\mathrm{Y}-\mathrm{OH}$ or $\mathrm{Fe}-\mathrm{OH}$ coordination polyhedra in the precursor [39]. 


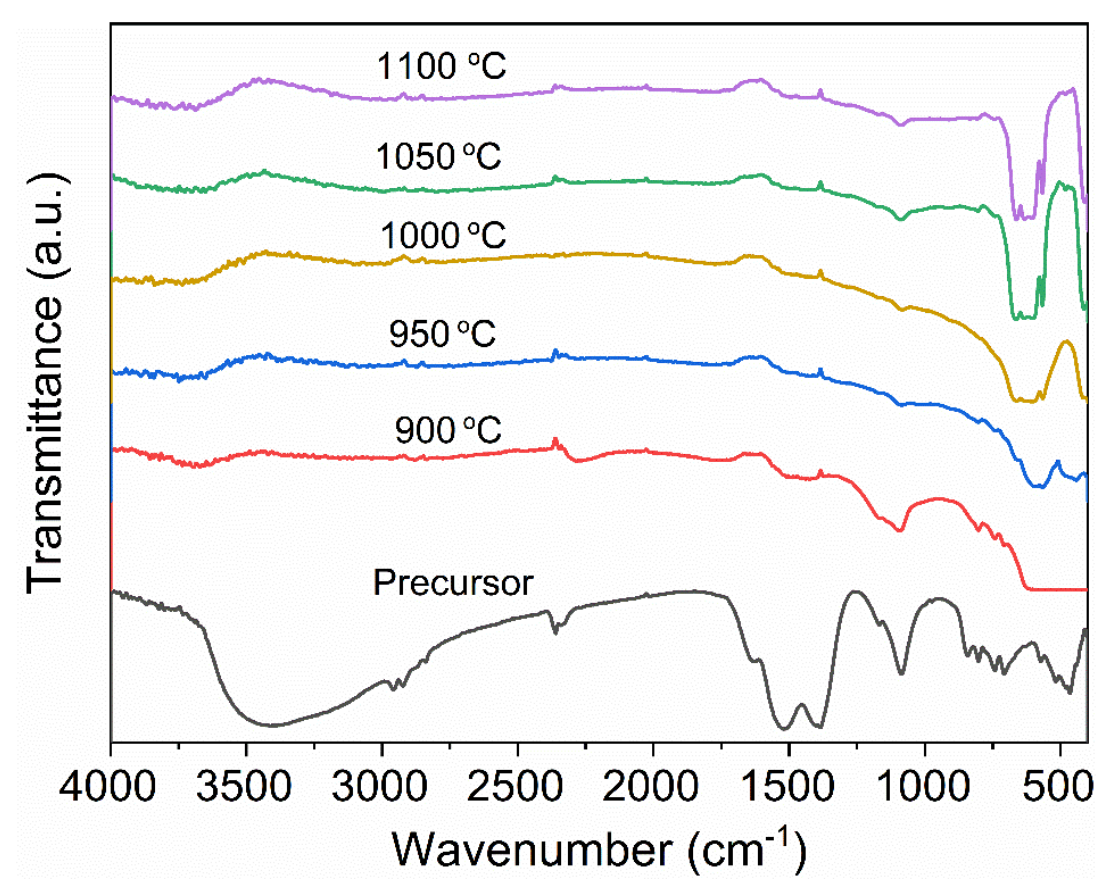

Figure 2. FTIR spectra of the precursor and the powders calcined at different temperatures for $4 \mathrm{~h}$.

For the powders calcined at $900{ }^{\circ} \mathrm{C}$, compared to the precursor, it can be noted that the bands centered at $841,802,742,707$, and $1086 \mathrm{~cm}^{-1}$ are remarkably reduced and those at 1384,1520 , and $1627 \mathrm{~cm}^{-1}$ nearly all disappear, suggesting the decompositions of $\mathrm{NH}_{4} \mathrm{NO}_{3}$ and the precipitates. However, a new broad band centered at $627 \mathrm{~cm}^{-1}$ could be found and most probably assigned to the characteristic vibrations of $\mathrm{Y}-\mathrm{O}$ or Fe-O bonds [40]. This result indicates an initial emergence of embryonic crystalline phases from the precursor calcined at $900{ }^{\circ} \mathrm{C}$ for $4 \mathrm{~h}$. With the temperature increasing to $950{ }^{\circ} \mathrm{C}$, a new weak band at $567 \mathrm{~cm}^{-1}$ could be noted and regarded as a representative absorption by YIG, meaning the starting formation of the YIG phase [37]. As to the powders calcined at 1000, 1050, and $1100{ }^{\circ} \mathrm{C}$, the distinct peaks at 662,603 , and $567 \mathrm{~cm}^{-1}$ ascribed to the stretching modes of Fe-O tetrahedrons in YIG can be clearly observed and show an increase in their intensities, suggesting the increasing crystallinity of YIG due to the enhanced thermal activation [41]. These results are in strong agreement with the XRD spectra shown in Figure 1.

The TG-DTA curves of the YIG precursor are given in Figure 3. The precursor undergoes several stages of decomposition during the heat treatment, with a total weight loss of $37.7 \%$. The broad endothermic peak located at $100{ }^{\circ} \mathrm{C}$ is attributed to the removal of molecular water and residual ethanol and the loss of ammonia groups, and the weight loss is about $24.4 \%$ [42]. A weight loss of approximately $11.7 \%$ occurs from $200{ }^{\circ} \mathrm{C}$ to $700{ }^{\circ} \mathrm{C}$, which is mainly ascribed to the further dehydration of the precursor and the elimination of carbonate and can be confirmed by the broad exothermic peak in the DTA curve caused by the decomposition of carbonate in the temperature range of $200-700{ }^{\circ} \mathrm{C}$. The exothermic peak at $752{ }^{\circ} \mathrm{C}$ indicates the crystallization of $\mathrm{YFeO}_{3}$. The weight loss from $700{ }^{\circ} \mathrm{C}$ to $800{ }^{\circ} \mathrm{C}$ is $1.1 \%$, which is attributed to the decomposition of residual carbonate. The succeeding exothermic peak at $1090{ }^{\circ} \mathrm{C}$ may be due to the crystallization of cubic YIG. The desulfurization of the precursor mainly takes place in the $1030-1100{ }^{\circ} \mathrm{C}$ range. There is no obvious weight loss in the TG curve above $1100{ }^{\circ} \mathrm{C}$, which indicates complete decomposition of the precursor [43]. 


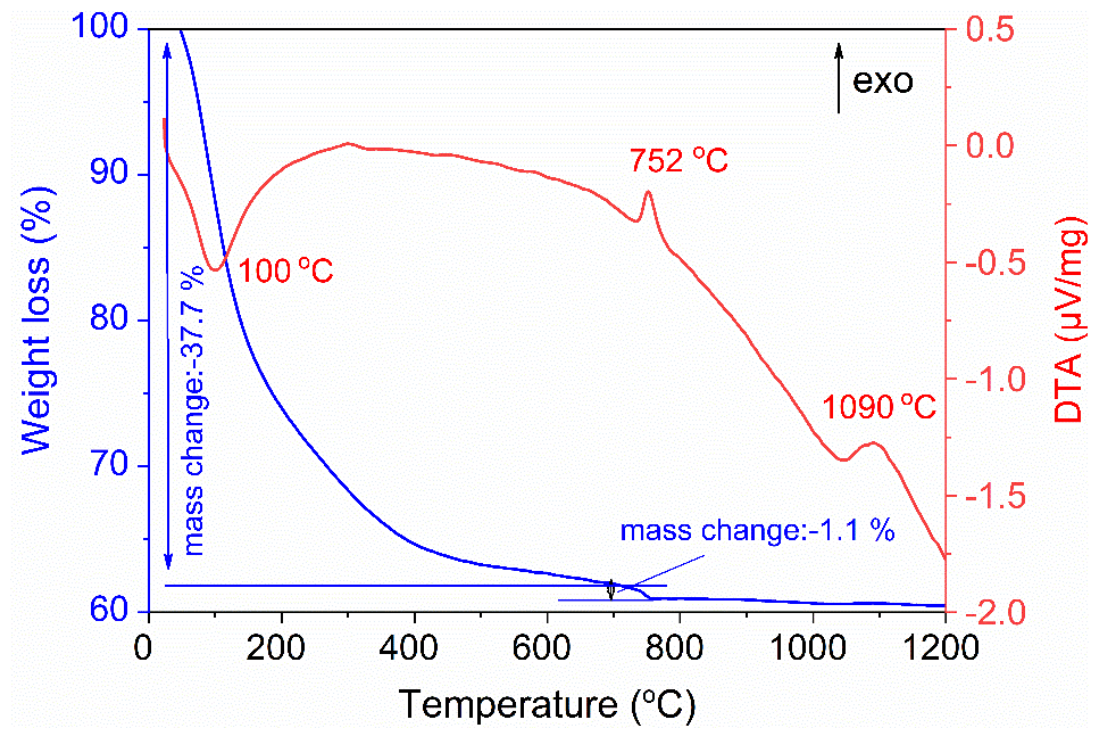

Figure 3. TG-DTA curves of the YIG precursor.

DTA shows that YIG is formed at $1090{ }^{\circ} \mathrm{C}$, while XRD shows that YIG is cubic at $1000^{\circ} \mathrm{C}$, which is due to the difference in the duration at the measuring temperature; that is, the resultant precursor for XRD studies was maintained at the calcination temperature for $4 \mathrm{~h}$, whereas the precursor for thermal analysis had no duration at the corresponding temperature [32,34].

Figure 4 shows the SEM morphologies of the precursor and YIG powders obtained with different calcination temperatures. The precursor approximately consists of spherical particles, which are relatively uniform in a wide range, but the powders exhibit certain soft agglomeration and poor crystallinity. For the powders calcined at $900{ }^{\circ} \mathrm{C}$ for $4 \mathrm{~h}$, compared with the precursor, the particle size is significantly increased, but the shape is still approximately spherical with a certain degree of adhesion, which is similar to a dumbbell. With the increase of the calcination temperature from $900^{\circ} \mathrm{C}$ to $950{ }^{\circ} \mathrm{C}$, the morphologies of the powders are similar, and obvious particle growth can be observed. When the calcination temperature rises to $1000{ }^{\circ} \mathrm{C}$, the morphology of the powders resembles a dendrite, and the crystallinity of the powders becomes stronger. The morphologies of the powders calcined at $1050-1100{ }^{\circ} \mathrm{C}$ are rod-shaped and regular, but the sintering neck quantity increases obviously, which leads to a decrease of the sintering activity. This phenomenon can be explained by the Ostwald ripening mechanism [44]. In order to reduce the specific surface area and improve the stability of the system, large particles will swallow small particles during the calcination process. The primary particle size of the calcined powder is calculated by the linear intercept method, which can be expressed as $\mathrm{D}_{\text {SEM }}$. The D $\mathrm{DEM}_{\text {SEM }}$ the powders calcinated at $900-1100{ }^{\circ} \mathrm{C}$ is $200,280,320,510$, and $530 \mathrm{~nm}$, respectively. The $\mathrm{D}_{\mathrm{SEM}}$ is larger than $\mathrm{D}_{\mathrm{XRD}}$ because some primary particles are tightly connected with each other, which are difficult to separate by ultrasonic. 

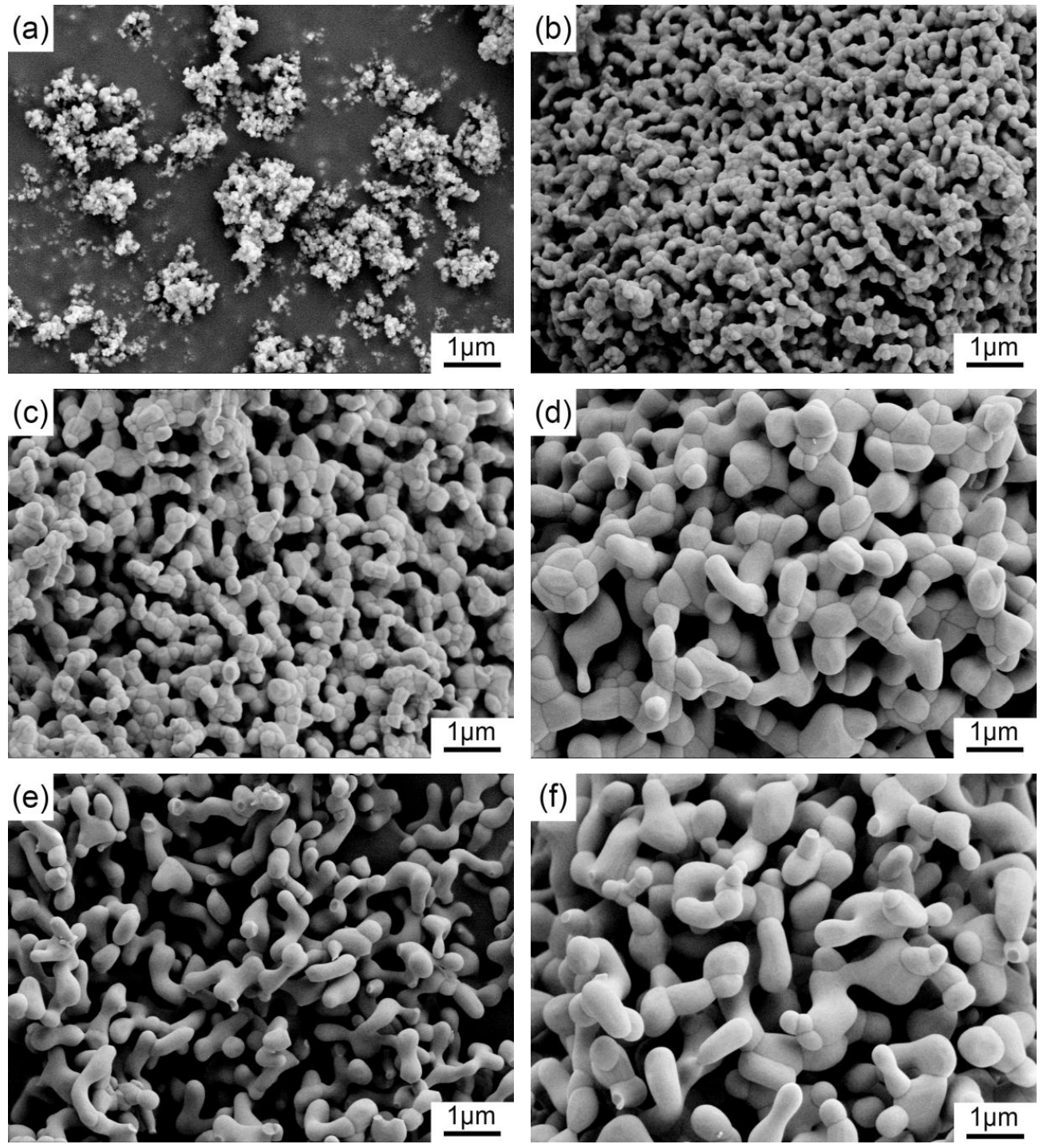

Figure 4. FESEM micrographs of the precursor and the powders calcined at different temperatures for 4 h: (a) precursor; (b) $900{ }^{\circ} \mathrm{C}$; (c) $950{ }^{\circ} \mathrm{C}$; (d) $100{ }^{\circ} \mathrm{C}$; (e) $1050{ }^{\circ} \mathrm{C}$; (f) $1100{ }^{\circ} \mathrm{C}$.

Figure 5 shows the densification curve of ceramics after air sintering at $1200-1400{ }^{\circ} \mathrm{C}$ for $10 \mathrm{~h}$ from powders calcined at different temperatures. It can be seen from Figure 5 that the overall relative density firstly increases and then decreases with the increase of the sintering temperature. When the sintering temperature increases from $1200{ }^{\circ} \mathrm{C}$ to $1250{ }^{\circ} \mathrm{C}$, the relative density of the ceramic increases rapidly, and a large number of pores are discharged from the sintered body. After sintering at $1300{ }^{\circ} \mathrm{C}$ for $10 \mathrm{~h}$, the relative densities of all ceramics show a downward trend. The main reason is that the high sintering temperature leads to the fast migration rate of the grain boundary, and the pores inside the ceramics cannot be discharged in time, and remain inside the grains, forming intragranular pores, which makes the relative density of YIG ceramics decrease [45]. Therefore, an excessively high sintering temperature has no beneficial effect on the ceramic in terms of densification. With the increasing calcination temperature of the powders, the relative density of the YIG ceramics sintered at $1200{ }^{\circ} \mathrm{C}$ increases first and then decreases. This may be due to the phase change of the powders calcined at 900 and $950^{\circ} \mathrm{C}$ during the preparation of ceramics, which retards the growth of grains. When the calcination temperature exceeds $1000{ }^{\circ} \mathrm{C}$, the sintering activity of the powders will decrease, resulting in a decrease of the density [46]. With the increase of the sintering temperature, the density difference of YIG ceramics calcined at different temperatures decreases gradually. 


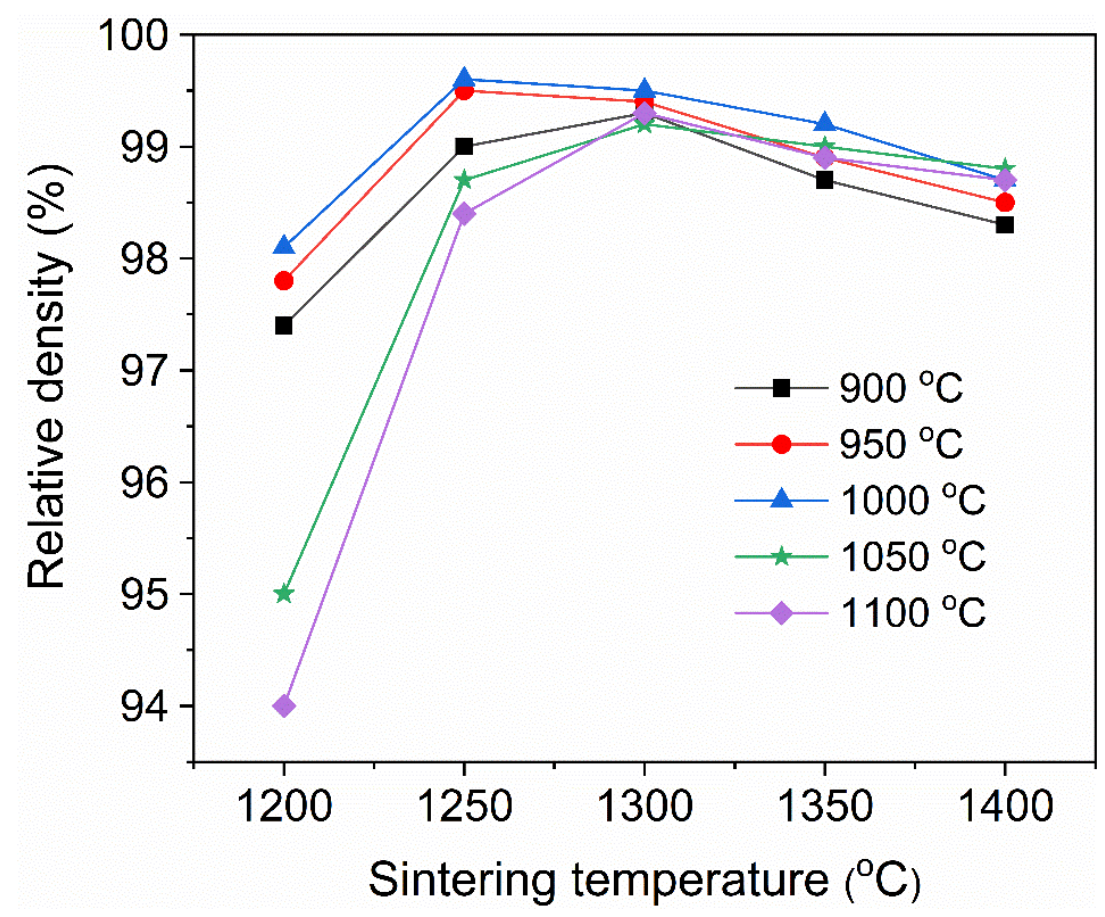

Figure 5. The relative density of the YIG ceramics sintered in air at $1200-1400{ }^{\circ} \mathrm{C}$ for $10 \mathrm{~h}$ using YIG powders calcined at $900-1100{ }^{\circ} \mathrm{C}$.

According to the above analysis, the precursor should be calcined at least above $1000{ }^{\circ} \mathrm{C}$ in order to ensure complete thermal decomposition of carbonate and sulfate in the as-prepared precursor, forming pure YIG powders. However, higher calcination temperature will cause a drastic increase in particle size and decrease in sinterability. As a result, we employed the $1000{ }^{\circ} \mathrm{C}$ calcined nanopowders for YIG transparent ceramic fabrication.

The microstructures of YIG ceramics obtained by air sintering at 1200, 1250, 1300, 1350, and $1400^{\circ} \mathrm{C}$ for $10 \mathrm{~h}$ using $1000^{\circ} \mathrm{C}$ calcined powders as raw material were characterized by FESEM, as shown in Figure 6. All the ceramic samples were thermally etched in a muffle furnace at $1100^{\circ} \mathrm{C}$ for $3 \mathrm{~h}$. There are numerous intergranular pores in YIG ceramics sintered at $1200{ }^{\circ} \mathrm{C}$. With the increase of the sintering temperature, the quantity of intragranular pores in the YIG ceramics increases gradually except the intergranular pores. As the sintering temperature increases, the grains of the ceramics grow up continuously. As shown in Figure $6 \mathrm{f}$, the average grain sizes of YIG ceramics sintered at $1200-1400{ }^{\circ} \mathrm{C}$ are $2.8,6.0,13.0,17.9$, and $22.1 \mu \mathrm{m}$, respectively. When the sintering temperature increases to 1350 and $1400{ }^{\circ} \mathrm{C}$, the size of the pores inside the YIG ceramics increases significantly. This may be because the internal air pressure of the pores increases with the increasing sintering temperature. When the internal air pressure increases to $2 \gamma / \mathrm{r}$ (r is the particle radius, $\gamma$ is the grain boundary energy), the driving force is not enough to meet the further sintering. At this time, if the sintering temperature further increases and the internal pressure is greater than $2 \mathrm{y} / \mathrm{r}$, the pores will expand and the relative density of the ceramics will be reduced, which is consistent with the densification curve in Figure 5. 

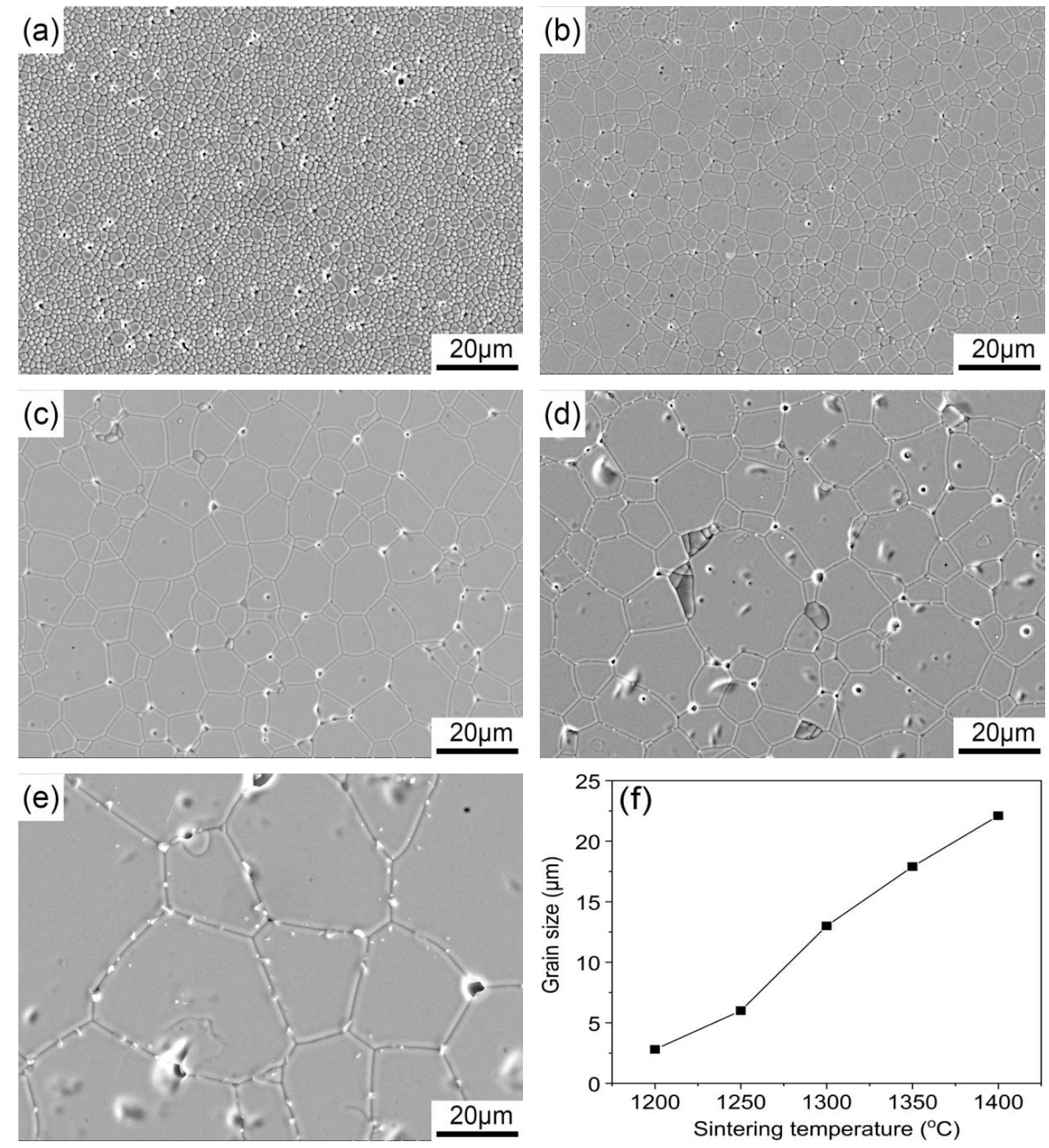

Figure 6. FESEM micrographs of thermally etched surfaces of YIG ceramics sintered at (a) 1200, (b) 1250, (c) 1300, (d) 1350, and (e) $1400{ }^{\circ} \mathrm{C}$ for $10 \mathrm{~h}$ and the average grain size (f) of YIG ceramics at each sintering temperature.

It can be clearly seen from Figure 6 that when the sintering temperature exceeds $1300{ }^{\circ} \mathrm{C}$, the secondary phase appears obviously in the YIG ceramics, and the amount of the secondary phase increases with the increase of the sintering temperature. The chemical composition of the secondary phase in the YIG ceramic (point A) is analyzed by the EDS, as shown in Figure 7. The result reveals that the element contents in the secondary phase are O: 63.48 at. $\%$, Fe: 36.52 at. $\%$, and Y: 0 at. $\%$, indicating that the secondary phase is iron oxides (see Figure 7A). This may be due to the loss of oxygen during high-temperature sintering, which leads to the stoichiometric imbalance of YIG ceramics [47]. The oxygen content needed to keep YIG valence equilibrium is greater than that in the environment. Therefore, the lack of oxygen causes the transformation of $\mathrm{Fe}^{3+}$ to $\mathrm{Fe}^{2+}$, leading to the formation of the secondary phase. 

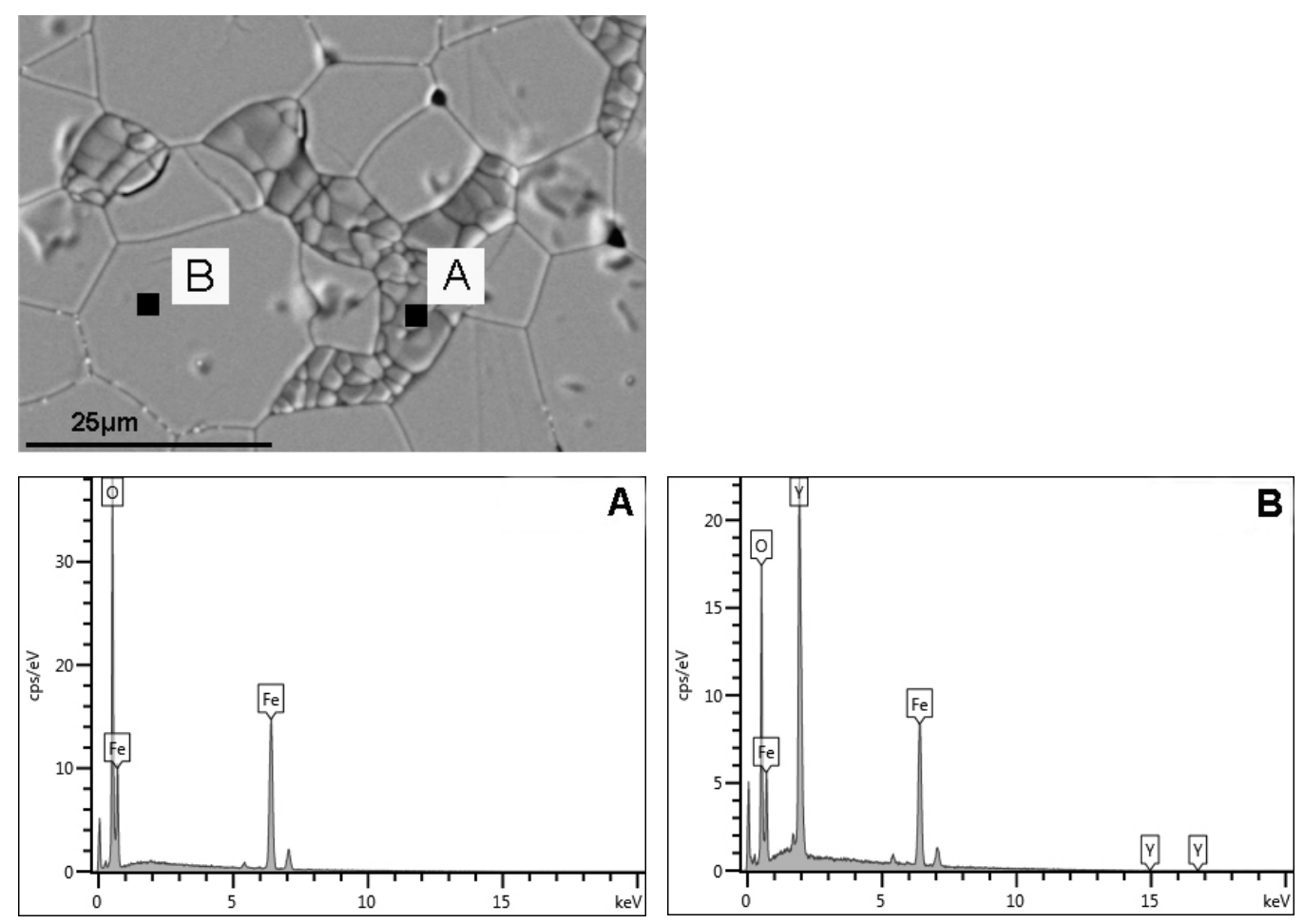

Figure 7. FESEM image and EDS patterns of the YIG ceramics sintered in air at $1400{ }^{\circ} \mathrm{C}$ for $10 \mathrm{~h}$.

Figure 8 shows the in-line transmittance curves of YIG ceramics sintered at 1250 and $1300{ }^{\circ} \mathrm{C}$ for $10 \mathrm{~h}$ and $1250^{\circ} \mathrm{C}$ for $30 \mathrm{~h}$ in air. It can be identified that the in-line transmittance of all ceramics is unsatisfactory, and the transmittance of the ceramics firstly increases and then decreases as the sintering temperature increases. As shown in Figure 9, we calculated the pore size distribution in ceramics sintered at $1250^{\circ} \mathrm{C}$ for $10 \mathrm{~h}$ from the linear intercept method. The size of the pores is comparable to the incident wavelength, giving rise to the occurrence of Mie scattering [48]. Therefore, the reason for the low transmittance is considered to be due to Mie scattering caused by residual pores. However, within the measurement range, the transmittance becomes lower as the wavelength becomes shorter. The fact that the transmission loss depends on the measuring wavelength cannot deny the influence of Rayleigh scattering in this case. When the temperature increases from $1200{ }^{\circ} \mathrm{C}$ to $1250{ }^{\circ} \mathrm{C}$, the transmittance of the ceramic increases in the range of $1000-3000 \mathrm{~nm}$. This is because the increase in the sintering temperature promotes the growth of grains and the discharge of some pores. When the sintering temperature is increased to $1300{ }^{\circ} \mathrm{C}$, the long-wave transmittance is significantly reduced. This is because in addition to pores, there are secondary phases in the ceramics at the scattering center, which will seriously affect the optical quality of the YIG ceramics, as shown in Figure 6c. We extended the holding time of ceramics sintered at $1250{ }^{\circ} \mathrm{C}$ in air to $30 \mathrm{~h}$. It can be seen from the figure that the in-line transmittance of the ceramics showed almost no change, which indicates that only increasing the sintering time cannot effectively eliminate the pores. 


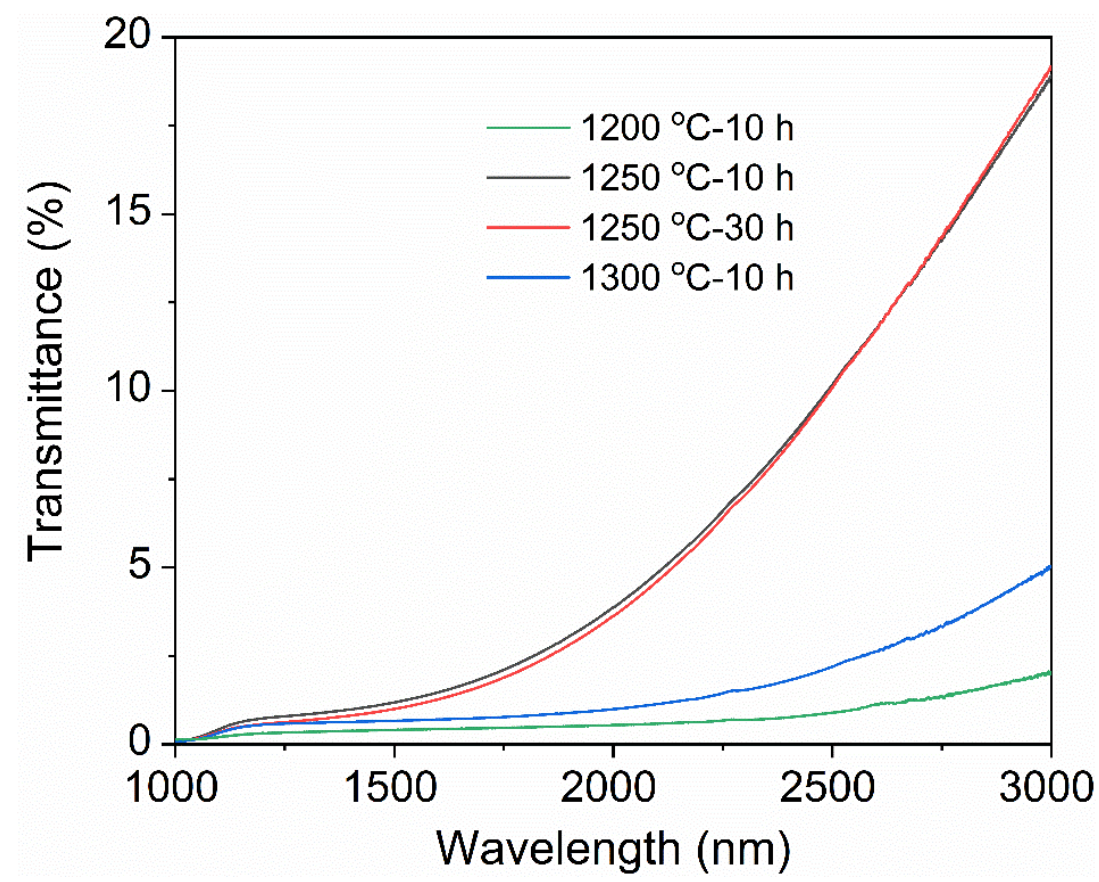

Figure 8. In-line transmittance curves of YIG transparent ceramics ( $0.3 \mathrm{~mm}$ thick) in air sintered at $1200-1300{ }^{\circ} \mathrm{C}$ for $10 \mathrm{~h}$ and $1250{ }^{\circ} \mathrm{C}$ for $30 \mathrm{~h}$.

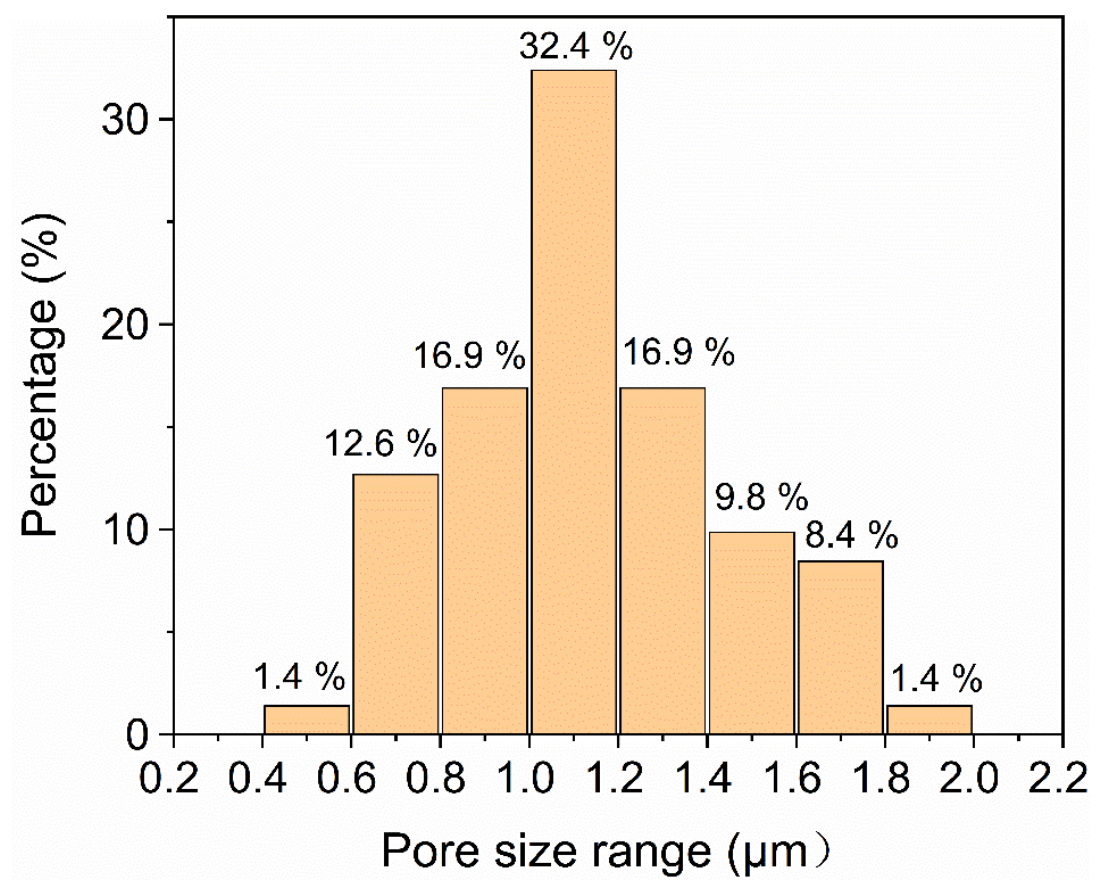

Figure 9. Pore size distribution of YIG ceramics sintered at $1250{ }^{\circ} \mathrm{C}$ for $10 \mathrm{~h}$.

However, the optical quality of the specimen is not good enough to meet the demand of the apparatus used in the near-mid infrared Faraday rotator. The relatively low transmittance of the prepared sample is mainly attributed to some optical scattering centers, such as residual pores, remaining in the ceramics. It is acknowledged that the hot isostatic pressing (HIP) post-treatment is an effective method to eliminate pores in the ceramic samples, which will be beneficial to the improvement of the optical quality of YIG ceramics. During the sintering process, the closed porosity is typically achieved when the theoretical density is greater than $92 \%$ depending on the grain size [49]. In our experiment, the YIG 
ceramics sintered from $1200{ }^{\circ} \mathrm{C}$ to $1400{ }^{\circ} \mathrm{C}$ fall within this range, which is probably suitable for the HIP post-treatment.

The heating element of the commonly used HIP equipment is graphite or tungsten, which is not resistant to oxygen, so the commonly used atmosphere is inert gas or reducing gas. However, YIG material is sensitive to the sintering atmosphere. We designed an experiment to verify the feasibility of pre-sintered ceramics for lower temperature HIP post-treatment under argon atmosphere. Firstly, the green body was sintered in air $\left(1250{ }^{\circ} \mathrm{C}\right.$ for $10 \mathrm{~h}$ ), and then the air-sintered ceramic sample was post-treated in argon atmosphere $\left(1100{ }^{\circ} \mathrm{C}\right.$ for $\left.3 \mathrm{~h}\right)$. The results show that the ceramics sintered in argon atmosphere are opaque at the wavelength of 800-3000 nm, the relative density is abnormal (more than $100 \%$ ), and the ceramics appear to be slightly discrete. In order to explain the above phenomenon, we used XRD to test the composition of the ceramic samples. As shown in Figure 10, except the YIG diffraction peak, no obvious impurity peak is observed in the pre-sintered ceramics. However, in the ceramics post-treated in argon atmosphere, besides the YIG diffraction peak, there were many $\mathrm{YIP}, \mathrm{Fe}_{3} \mathrm{O}_{4}$, and $\mathrm{Fe}_{2} \mathrm{O}_{3}$ diffraction peaks. The phase transition may be caused by low oxygen partial pressure during argon atmosphere sintering. Under low oxygen partial pressure, $\mathrm{Fe}^{3+}$ transforms into $\mathrm{Fe}^{2+}$ and new phases are formed. These secondary phases lead to a lot of light absorption and scattering, which seriously affects the optical quality of ceramics. Therefore, it is not feasible to make the YIG ceramics completely dense by HIP post-treatment in argon atmosphere.

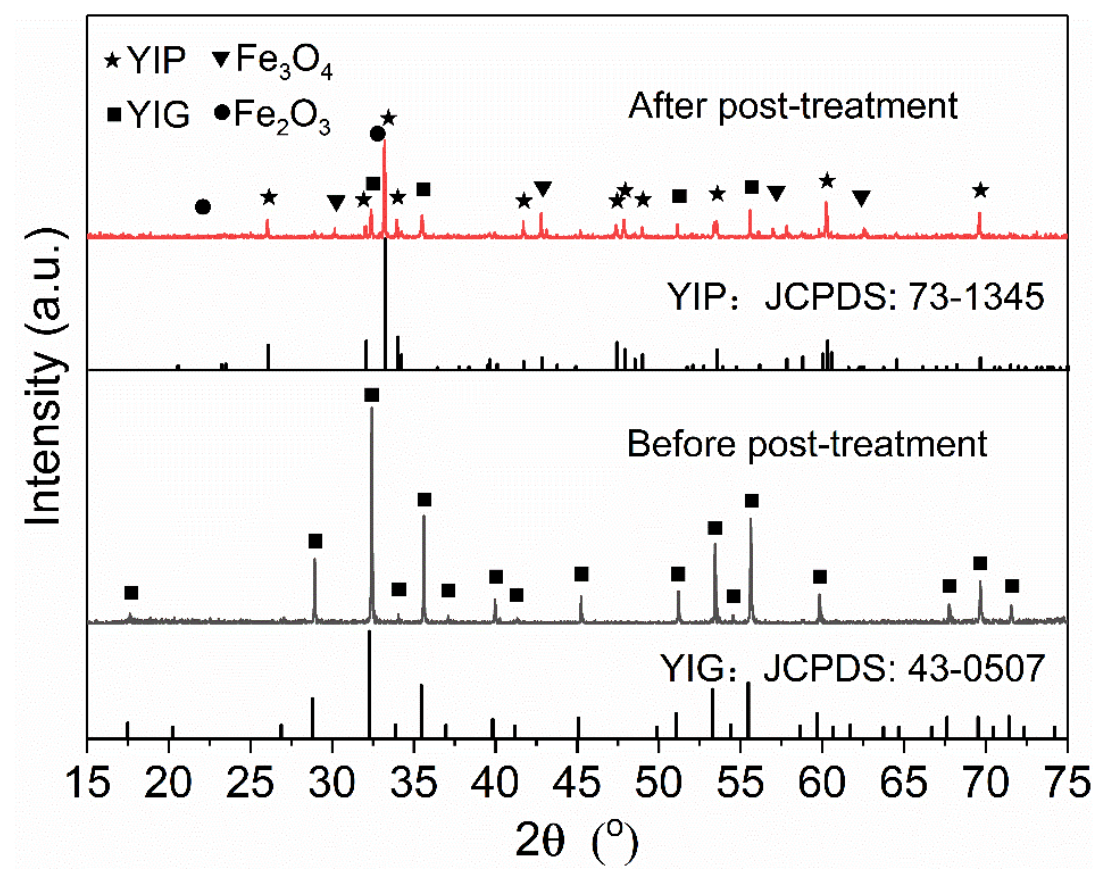

Figure 10. XRD patterns of the YIG ceramics before and after post-treatment in argon atmosphere.

\section{Materials and Methods}

In the present work, YIG ceramics were made from high-purity powders synthesized via the coprecipitation method. In brief, $\mathrm{Y}\left(\mathrm{NO}_{3}\right)_{3}$ solution was prepared by dissolving $\mathrm{Y}_{2} \mathrm{O}_{3}$ (99.99\%, Changting Jinlong Rare Earth Co., Ltd., Changting, China) in the high-purity nitric acid. Fe( $\left(\mathrm{NO}_{3}\right)_{3}$ solution was prepared by dissolving $\mathrm{Fe}\left(\mathrm{NO}_{3}\right)_{3} \bullet 9 \mathrm{H}_{2} \mathrm{O}(99.9 \%$, Shanghai Macklin Biochemical Technology Co., Ltd. Shanghai, China) in deionized water, and a certain amount of nitric acid was added into the solution to prevent $\mathrm{Fe}^{3+}$ ion hydrolysis. The metal nitrates were mixed according to the stoichiometric ratio of $\mathrm{Y}_{3} \mathrm{Fe}_{5} \mathrm{O}_{12}$ and the solution concentration was further adjusted to $0.3 \mathrm{~mol} / \mathrm{L}$ for $\mathrm{Fe}^{3+}$ with deionized water. The solution of $1.5 \mathrm{~mol} / \mathrm{L} \mathrm{NH}_{4} \mathrm{HCO}_{3}$ (AHC) (Analytical grade, Aladdin, Shanghai, China) was prepared as the precipitant. Ammonium sulfate $(99.0 \%$, Sinopharm Chemical Reagent 
Co., Ltd., Shanghai, China) was added into the AHC solution as the dispersant. Then, $500 \mathrm{~mL}$ of the mixed metal solution were dropped into $800 \mathrm{~mL}$ of the AHC solution at a speed of $20 \mathrm{~mL} / \mathrm{min}$ under mild stirring at room temperature. After aging for $1 \mathrm{~h}$, the resultant slurry was washed three times with deionized water and rinsed twice with absolute ethanol. Then, the precursor was dried at $70{ }^{\circ} \mathrm{C}$ for $48 \mathrm{~h}$, which was subsequently calcined in the temperature range of $900-1100{ }^{\circ} \mathrm{C}$ for $4 \mathrm{~h}$. Finally, the powders were uniaxially dry-pressed into pellets at $20 \mathrm{MPa}$ followed by being cold isostatically pressed at $250 \mathrm{MPa}$. The green bodies were sintered at $1250{ }^{\circ} \mathrm{C}$ for $10 \mathrm{~h}$ in air. The specimens were mirror-polished on both sides to a 0.3-mm thickness for further testing.

Phase identification of the powders was identified by X-ray diffraction (XRD, Model D/max2200 PC, Rigaku, Japan). XRD analysis was performed on a Huber Imaging Plate Guinier Camera G670 (Cu Ka1 radiation, $\mathrm{k}=1.54056 \AA, 40 \mathrm{kV} / 30 \mathrm{~mA}$, Ge monochromator). The $2 \theta$ for all data ranged from $10^{\circ}$ to $80^{\circ}$ with a $0.02^{\circ}$ step size. The test was carried out at room temperature. The chemical compositions of the powders calcined at different temperature were examined by the Fourier transform infrared spectrometer. The test was carried out at room temperature (FTIR, Bruker VERTEX 70 spectrophotometer, Ettlingen, Germany). Thermogravimetry analysis and differential thermal analysis (TG-DTA) of the precursor were performed on a TG-DTA analyzer (Thermo plus EVO II, Rigaku, Japan) in flowing air atmosphere at a heating rate of $10^{\circ} \mathrm{C} / \mathrm{min}$. The morphology of powders and the microstructures of the thermally etched surfaces of the ceramics were observed by a field emission scanning electron microscopy. The test was carried out at room temperature (FESEM, S-8220, Hitachi, Japan). Grain sizes were determined from SEM images using the linear intercept method. The in-line transmittance of mirror-polished YIG ceramic samples was measured with a UV-VIS-NIR spectrophotometer. The test was carried out at room temperature (Model Cray-5000, Varian, CA, USA).

\section{Conclusions}

The YIG powders were synthesized by the coprecipitation method, and YIG ceramics with a certain transmittance were prepared by air pressureless sintering. YIG powders were obtained under different calcination temperatures. According to the phase, thermal, and morphology analysis of the powders, the precursor should be calcined above at least $1000{ }^{\circ} \mathrm{C}$ in order to ensure complete thermal decomposition of carbonate and sulfate in the prepared precursor and form pure YIG powders. YIG ceramics prepared by air sintering at $1250{ }^{\circ} \mathrm{C}$ from powders calcinated at $1000{ }^{\circ} \mathrm{C}$ showed the highest in-line transmittance in the range of 1000-3000 nm, but still showed pores inside the ceramic. When the sintering temperature exceeded $1300^{\circ} \mathrm{C}$, the the oxygen content needed to keep YIG valence equilibrium is greater than that in the environment. Therefore, the lack of oxygen causes the transformation of $\mathrm{Fe}^{3+}$ to $\mathrm{Fe}^{2+}$, leading to the formation of the secondary phase. These pores and the secondary phase seriously affect the transmittance of the YIG ceramics. In order to verify the feasibility of eliminating the residual pores through HIP post-treatment in an argon atmosphere, the ceramic sintered at $1250^{\circ} \mathrm{C}$ was pressureless post-treated at $1100{ }^{\circ} \mathrm{C}$ in the argon atmosphere. The sintered ceramic underwent phase changes, indicating that YIG ceramics will also undergo phase changes when processed under low oxygen partial pressure. In order to obtain high optical quality YIG ceramics, hot pressing (HP) and HIP in oxygen atmosphere will be used to eliminate residual pores as well as maintain pure YIG phase in our future work. The development of yttrium iron garnet-based ceramics will become a huge driving force for future technological innovation in optical communication and information processing systems.

Author Contributions: Conceptualization, J.L. and Y.Y.; methodology and software, Y.Y.; validation, X.L. (Xiaoying Li); formal analysis, Y.Y., Z.L. and F.T.; investigation, Y.Y. and D.H.; resources, J.L.; data curation, Y.Y. and X.L. (Xin Liu); writing —original draft preparation and writing-review and editing, J.L., Y.Y. and D.Z.; visualization, L.Z. and P.C.; supervision, project administration and funding acquisition, J.L. All authors have read and agreed to the published version of the manuscript. 
Funding: This research received no external funding.

Data Availability Statement: The data presented in this study are available in this article.

Acknowledgments: This research was funded by National Key R\&D Program of China (Grant No. 2017YFB0310500), the Special Exchange Program of Chinese Academy of Sciences (Plan B), the key research project of the frontier science of the Chinese Academy of Sciences (No. QYZDB-SSW-JSC022).

Conflicts of Interest: The authors declare no conflict of interest.

\section{References}

1. Li, J.; Dai, J.W.; Pan, Y.B. Research progress on magneto-optical transparent ceramics. J. Inorg. Mater. 2018, 33, 1-8.

2. Onbasli, M.; Beran, L.; Zahradník, M.; Kučera, M.; Antoš, R.; Mistrík, J.; Dionne, G.; Veis, M.; Ross, C. Optical and magneto-optical behavior of Cerium Yttrium Iron Garnet thin films at wavelengths of 200-1770 nm. Sci. Rep. 2016, 6, 23640. [CrossRef]

3. Vojna, D.; Slezák, O.; Lucianetti, A.; Mocek, T. Verdet constant of magneto-active materials developed for high-power faraday devices. Appl. Sci. 2019, 9, 3160. [CrossRef]

4. Yang, H.H.; Zhu, Z.L. Magneto-optical glass mixed with $\mathrm{Tb}^{3+}$ ions: High Verdet constant and luminescence properties. J. Lumin. 2021, 231, 117804. [CrossRef]

5. Vojna, D.; Slezák, O.; Yasuhara, R.; Furuse, H.; Lucianetti, A.; Mocek, T. Faraday rotation of $\mathrm{Dy}_{2} \mathrm{O}_{3}, \mathrm{CeF}_{3}$ and $\mathrm{Y}_{3} \mathrm{Fe}_{5} \mathrm{O}_{12}$ at the mid-infrared wavelengths. Materials 2020, 13, 5324. [CrossRef] [PubMed]

6. Li, J.; Tian, F.; Liu, Z.Y. Research progress and prospects of mid-infrared laser ceramics. J. Synth. Cryst. 2020, 49, $1467-1487$.

7. Li, X.Y.; Liu, Q.; Hu, Z.W.; Jiang, N.; Shi, Y.; Li, J. Influence of ammonium hydrogen carbonate to metal ions molar ratio on co-precipitated nanopowders for TGG transparent ceramics. J. Inorg. Mater. 2019, 34, 791-796. [CrossRef]

8. Liu, Q.; Li, X.Y.; Dai, J.W.; Yang, Z.X.; Xie, T.F.; Li, J. Fabrication and characterizations of $\left(\mathrm{Tb}_{1-\mathrm{x}} \mathrm{Pr}_{\mathrm{x}}\right)_{3} \mathrm{Al}_{5} \mathrm{O}_{12} \mathrm{magneto} \mathrm{optical}$ ceramics for Faraday isolators. Opt. Mater. 2018, 84, 330-334. [CrossRef]

9. Aung, Y.L.; Ikesue, A. Development of optical grade $\left(\mathrm{Tb}_{\mathrm{x}} \mathrm{Y}_{1-\mathrm{x}}\right)_{3} \mathrm{Al}_{5} \mathrm{O}_{12}$ ceramics as Faraday rotator material. J. Am. Ceram. Soc. 2017, 100, 4081-4087. [CrossRef]

10. Lin, H.; Zhou, S.M.; Teng, H. Synthesis of $\mathrm{Tb}_{3} \mathrm{Al}_{5} \mathrm{O}_{12}$ (TAG) transparent ceramics for potential magneto-optical applications. Opt. Mater. 2011, 33, 1833-1836. [CrossRef]

11. Dai, J.W.; Pan, Y.B.; Xie, T.F.; Kou, H.M.; Li, J. Highly transparent $\mathrm{Tb}_{3} \mathrm{Al}_{5} \mathrm{O}_{12}$ magneto-optical ceramics sintered from coprecipitated powders with sintering aids. Opt. Mater. 2018, 78, 370-374. [CrossRef]

12. Rubinstein, C.B.; Van Uitert, L.G.; Grodkiewicz, W.H. Magneto-optical properties of rare earth (III) aluminum garnets. J. Appl. Phys. 1964, 35, 3069-3070. [CrossRef]

13. Villaverde, A.B.; Donatti, D.A.; Bozinis, D.G. Terbium gallium garnet Verdet constant measurements with pulsed magnetic field. J. Phys. C Solid State Phys. 1978, 11, L495-L498. [CrossRef]

14. Sekijima, T.; Kishimoto, H.; Fujii, T.; Wakino, K.; Okada, M. Magnetic, Optical and microwave properties of rare-earth-substituted fibrous yttrium iron garnet single crystals grown by floating zone method. Jpn. J. Appl. Phys. 1999, 38, 5874-5878. [CrossRef]

15. Kimura, S.; Kitamura, K.; Shindo, I. Growth of rare earth garnet crystals by the floating zone method. J. Cryst. Growth 1983, 65, 543-548. [CrossRef]

16. Jin, W.Z.; Gai, L.Y.; Li, C.; Lin, H.; Su, L.B.; Zeng, F.M.; Wu, A.H. Crystal growth and characterization of $\mathrm{Ce}_{\mathrm{x}} \mathrm{Y}_{3-\mathrm{x}} \mathrm{Fe}_{5} \mathrm{O}_{12} \operatorname{single}$ crystal by optical floating zone method. Phys. B 2020, 588, 412168. [CrossRef]

17. Basavad, M.; Shokrollahi, H.; Golkari, M. Effect of thermal cycle and Bi/Eu doping on the solubility of Ce in YIG. Ceram. Int. 2020, 46, 20144-20154. [CrossRef]

18. Wittekoek, S.; Robertson, J.M.; Popma, T.J.A.; Bongers, P.F. Faraday rotation and optical absorption of epitaxial films of $\mathrm{Y}_{3-\mathrm{x}} \mathrm{Bi}_{\mathrm{x}} \mathrm{Fe}_{5} \mathrm{O}_{12}$. AIP Conf. Proc. 1973, 10, 1418-1422.

19. Sekijima, T.; Itoh, H.; Fujii, T.; Wakino, K.; Okada, M. Influence of growth atmosphere on solubility limit of Ce ${ }^{3+}$ ions in Ce-substituted fibrous yttrium iron garnet single crystals. J. Cryst. Growth 2001, 229, 409-414. [CrossRef]

20. Zhang, X.W.; Zhang, S.Y.; Han, G.R. Growth and characterization of magneto-optical single-crystal ReYbBiIG with temperaturestabilized Faraday rotation. J. Magn. Magn. Mater. 2002, 246, 67-72. [CrossRef]

21. Sekijima, T.; Satoh, H.; Tahara, K.; Fujii, T.; Wakino, K.; Okada, M. Growth of fibrous YIG single crystals by the self-adjusting solvent FZ method. J. Cryst. Growth 1998, 193, 446-450. [CrossRef]

22. Lee, S.H.; Kochawattana, S.; Messing, G.L.; Dumm, J.Q.; Quarles, G.; Castillo, V. Solid-state reactive sintering of transparent polycrystalline Nd:YAG ceramics. J. Am. Ceram. Soc. 2006, 89, 1945-1950. [CrossRef]

23. Sanghera, J.; Kim, W.; Villalobos, G.; Shaw, B.; Baker, C.; Frantz, J.; Sadowski, B.; Aggarwal, I. Ceramic laser materials: Past and present. Opt. Mater. 2013, 35, 693-699. [CrossRef]

24. Ikesue, A.; Aung, Y.L. Development of optical grade polycrystalline YIG ceramics for faraday rotator. J. Am. Ceram. Soc. 2018, 101, 5120-5126. [CrossRef]

25. Aung, Y.L.; Ikesue, A.; Watanabe, T.; Makikawa, S.; Iwamoto, Y. Bi substituted YIG ceramics isolator for optical communication. J. Alloy. Compd. 2019, 811, 152059. [CrossRef]

26. Aung, Y.L.; Ikesue, A. Transparent $\mathrm{Tb}_{3} \mathrm{Fe}_{5} \mathrm{O}_{12}$ ceramics as Mid-IR isolator. J. Alloy. Compd. 2019, 773, 739-742. [CrossRef] 
27. Ikesue, A.; Aung, Y.; Yasuhara, R.; Iwamoto, Y. Giant Faraday rotation in heavily Ce-doped YIG bulk ceramics. J. Eur. Ceram. Soc. 2020, 40, 6073-6078. [CrossRef]

28. Li, X.Y.; Liu, Q.; Pan, H.M.; Jiang, N.; Yang, Z.X.; Xie, T.F.; Wu, L.X.; Li, J. Transparent Tb ${ }_{3} \mathrm{Ga}_{5} \mathrm{O}_{12}$ magneto-optical ceramics sintered from co-precipitated nano-powders calcined at different temperatures. Opt. Mater. 2019, 90, 26-32. [CrossRef]

29. Chen, P.H.; Liu, Q.; Li, X.Y.; Feng, Y.G.; Chen, X.P.; Liu, X.; Wu, L.X.; Li, J. Influence of terminal pH value on co-precipitated nanopowders for yttria-stabilized $\mathrm{ZrO}_{2}$ transparent ceramics. Opt. Mater. 2019, 98, 109475. [CrossRef]

30. Liu, Z.Y.; Toci, G.; Pirri, A.; Patrizi, B.; Feng, Y.G.; Wei, J.B.; Wu, F.; Yang, Z.X.; Vannini, M.; Li, J. Fabrication, microstructures, and optical properties of $\mathrm{Yb}: \mathrm{Lu}_{2} \mathrm{O}_{3}$ laser ceramics from co-precipitated nano-powders. J. Adv. Ceram. 2020, 9, 674-682. [CrossRef]

31. Belous, A.; Tovstolytkin, A.; Fedorchuk, O.; Shlapa, Y.; Solopan, S.; Khomenko, B. Al-doped yttrium iron garnets $\mathrm{Y}_{3} \mathrm{AlFe}_{4} \mathrm{O}_{12}$ : Synthesis and properties. J. Alloy. Compd. 2021, 856, 158140. [CrossRef]

32. Hu, D.J.; Liu, X.; Liu, Z.Y.; Li, X.Y.; Tian, F.; Zhu, D.Y.; Yang, Z.X.; Wu, L.X.; Li, J. Fabrication of Dy ${ }_{2} \mathrm{O}_{3}$ transparent ceramics by vacuum sintering using precipitated powders. Magnetochemistry 2021, 7, 6. [CrossRef]

33. Dai, J.W.; Snetkov, I.L.; Palashov, O.V.; Pan, Y.B.; Kou, H.M.; Li, J. Fabrication, microstructure and magneto-optical properties of $\mathrm{Tb}_{3} \mathrm{Al}_{5} \mathrm{O}_{12}$ transparent ceramics. Opt. Mater. 2016, 62, 205-210. [CrossRef]

34. Liu, J.L.; Jin, Q.M.; Wang, S.Y.; Yu, P.; Zhang, C.; Luckhardt, C.; Su, Z.J.; Barua, R.; Harris, V.G. An insight into formation mechanism of rapid chemical co-precipitation for synthesizing yttrium iron garnet nano powders. Mater. Chem. Phys. 2018, 208, 169-176. [CrossRef]

35. Monshi, A.; Foroughi, M.R.; Monshi, M.R. Modified Scherrer equation to estimate more accurately nano-crystallite size using XRD. World J. Nano Sci. Eng. 2012, 2, 154-160. [CrossRef]

36. Dai, J.W.; Pan, Y.B.; Chen, H.H.; Xie, T.F.; Kou, H.M.; Li, J. Fabrication of $\mathrm{Tb}_{3} \mathrm{Al}_{5} \mathrm{O}_{12}$ transparent ceramics using co-precipitated nanopowders: The influence of ammonium hydrogen carbonate to metal ions molar ratio. Ceram. Int. 2017, 43, 14457-14463. [CrossRef]

37. Lu, B.; Wu, S.F.; Cheng, H.M.; Ye, R.J.; Cai, X.Y.; Wang, M.Y.; Wang, Y. Binary transparent $\left(\mathrm{Ho}_{1-\mathrm{x}} \mathrm{Dy}_{\mathrm{x}}\right)_{2} \mathrm{O}_{3}$ ceramics: Compositional influences on particle properties, sintering kinetics and Faraday magneto-optical effects. J. Eur. Ceram. Soc. 2021, 41, 2826-2833. [CrossRef]

38. Dai, J.W.; Pan, Y.B.; Wang, W.; Wei, L.; Xie, T.F.; Kou, H.M.; Li, J. Fabrication of $\mathrm{Tb}_{3} \mathrm{Al}_{5} \mathrm{O}_{12}$ transparent ceramics using coprecipitated nanopowders. Opt. Mater. 2017, 73, 38-44. [CrossRef]

39. Zhang, W.; Guo, C.J.; Ji, R.J.; Fang, C.X.; Zeng, Y.W. Low-temperature synthesis and microstructure-property study of single-phase yttrium iron garnet (YIG) nanocrystals via a rapid chemical coprecipitation. Mater. Chem. Phys. 2011, 125, 646-651. [CrossRef]

40. Muliuoliene, I.; Mathur, S.; Jasaitis, D.; Shen, H.; Sivakov, V.; Rapalaviciute, R.; Beganskiene, A.; Kareiva, A. Evidence of the formation of mixed-metal garnets via sol-gel synthesis. Opt. Mater. 2003, 22, 241-250. [CrossRef]

41. Azis, R.S.; Syazwan, M.M.; Shahrani, N.M.M.; Hapishah, A.N.; Nazlan, N.; Idris, F.M.; Ismail, I.; Zulkimi, M.M.M.; Ibrahim, I.R.; Abbas, Z.; et al. Influence of sintering temperature on the structural, electrical and microwave properties of yttrium iron garnet (YIG). J. Mater. Sci. Mater. Electron. 2018, 29, 8390-8401. [CrossRef]

42. Huang, X.Y.; Liu, Y.M.; Liu, Y.; Li, X.Y.; Feng, Y.G.; Chen, X.P.; Chen, P.H.; Liu, X.; Xie, T.F.; Li, J. Fabrication and characterizations of $\mathrm{Yb}$ :YAG transparent ceramics using alcohol-water co-precipitation method. J. Inorg. Mater. 2021, 2, 1-8. [CrossRef]

43. Ahn, Y.S.; Han, M.H.; Kim, C.O. Synthesis of yttrium iron garnet precursor particles by homogeneous precipitation. J. Mater. Sci. 1996, 31, 4233-4240. [CrossRef]

44. Dai, J.W.; Pan, Y.B.; Chen, H.H.; Xie, T.F.; Kou, H.M.; Li, J. Synthesis of $\mathrm{Tb}_{4} \mathrm{O}_{7}$ nanopowders by the carbonate-precipitation method for $\mathrm{Tb}_{3} \mathrm{Al}_{5} \mathrm{O}_{12}$ magneto-optical ceramics. Opt. Mater. 2017, 73, 706-711. [CrossRef]

45. Zhang, L.; Yang, J.; Yu, H.Y.; Pan, W. High performance of La-doped $\mathrm{Y}_{2} \mathrm{O}_{3}$ transparent ceramics. J. Adv. Ceram. 2020, 9, 493-502. [CrossRef]

46. Li, J.; Liu, J.; Liu, B.L.; Liu, W.B.; Zeng, Y.P.; Ba, X.W.; Xie, T.F.; Jiang, B.X.; Liu, Q.; Pan, Y.B.; et al. Influence of heat treatment of powder mixture on the microstructure and optical transmission of Nd:YAG transparent ceramics. J. Eur. Ceram. Soc. 2014, 34, 2497-2507. [CrossRef]

47. Nazlan, R.; Ismail, I.; Azis, R.S.; Abbas, Z.; Ibrahim, I.R.; Idris, F.M.; Shafiee, F.N.; Aripin, A.S.; Busra, N.A.N. Dependence of magnetic and microwave loss on evolving microstructure in yttrium iron garnet. J. Mater. Sci. Mater. Electron. 2018, 29, 8688-8700. [CrossRef]

48. Krell, A.; Klimke, J.; Hutzler, T. Transparent compact ceramics: Inherent physical issues. Opt. Mater. 2009, 31, 1144-1150. [CrossRef]

49. Seeley, Z.M.; Kuntz, J.D.; Cherepy, N.J.; Payne, S.A. Transparent $\mathrm{Lu}_{2} \mathrm{O}_{3}$ :Eu ceramics by sinter and HIP optimization. Opt. Mater. 2011, 33, 1721-1726. [CrossRef] 